\title{
Vladimír Hanuš, June 5, 1923-July 3, 2009
}

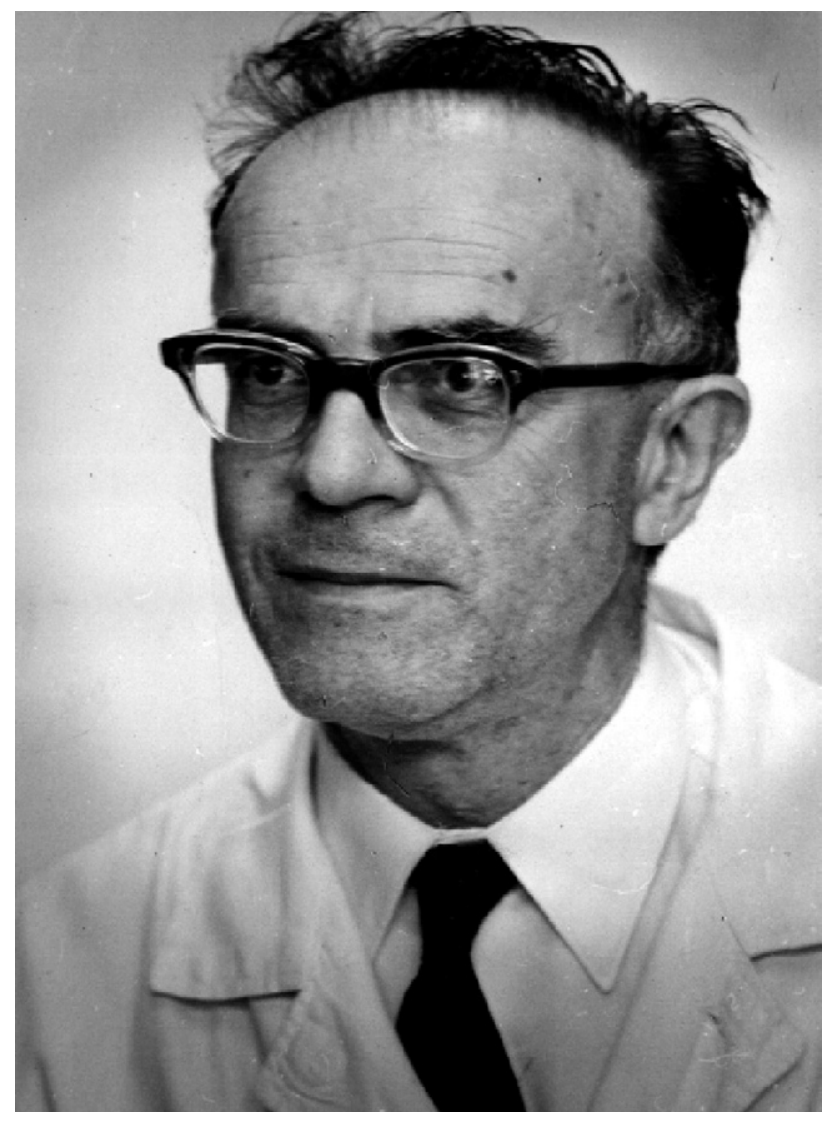

$\mathrm{D}$ r. Vladimír Hanuš, a Czech physical chemist of world renown and co-founder (with the late Dr. Vladimír Čermák) of mass spectrometry in Czechoslovakia, died on July 3, 2009, shortly after his $86^{\text {th }}$ birthday. His entire scientific carrier was connected with the Institute of Physical Chemistry (now J. Heyrovský Institute of Physical Chemistry, Academy of Science of the Czech Republic) in Prague, where he served also for many years as Department Head and Vice-Director. He was internationally known even before the age of thirty for his work in electrochemistry with Professor Heyrovský and Professor Brdička. In the early 1950s, he started research in a brand new area, building with Dr. V. Čermák the first mass spectrometer in Czechoslovakia. His experience in organic chem-

Published online September 23, 2009

Address reprint requests to Professor Zdenek Herman, J. Heyrovsky Institute of Physical Chemistry, V. Cermák Laboratory, Academy of Science of the Czech Republic, Dolejskova 3, CZ-18223 Prague 8, Czech Republic. E-mail: zdenek.herman@jh-inst.cas.cz istry led him from the very start to applications of this method in organic chemistry, and he was one of the pioneers in this area in the late 1950s. He was among the first to introduce a direct inlet system for nonvolatile samples that revolutionized mass spectrometric structure elucidation of steroids, alkaloids, and other natural products. His research was very extensive and concerned unimolecular fragmentation and rearrangements of organic ions, analysis and structure elucidation of organic and bio-organic compounds, as well as numerous applications of mass spectrometry in biology, medicine, environmental analysis, and toxicology. We are losing in him a highly respected senior colleague, teacher, and friend.

\section{Zdenek Herman}

J. Heyrovský Institute of Physical Chemistry, Academy of Sciences, Prague, Czech Republic

František Tureček University of Washington, Seattle, Washington, USA 